\title{
パラタングステン酸アンモニウムの熱分解における \\ 超微粒タングステン酸化物の生成機構
}

\section{山本 良治, 松本 明英 \\ 本川惺, 志垣 憲良}

東京タングステン仳粉末製品事業部，テ931 富山市岩頪古志町2.

\section{Formation Mechanism of Ultrafine Tungsten Oxide Particle during Thermal Decomposition of Ammonium Paratungstate}

\author{
Yoshiharu Yamamoto, Akihide Matsumoto \\ Satoru Honkawa and Noriyoshi Shigaki
}

Refinery \& Hardmetal Division, Tokyo Tungsten Co., Ltd., 2 iwasekoshimachi, Toyama 931.

Received January 26, 1993

The determing factor of tungsten oxide particle size during thermal decomposition of monoclinic ammonium paratungstate (APT) has been studied. APT was decomposed by thermobalance in nitrogen,oxygen,air and mixture of ammonia and nitrogen atmosphere. Formation mechanism of ultrafine tungsten oxide particle was investigated using $X$-ray diffraction analysis, scanning electron microscopy and specific surface area measurement.

The relationship of particle size between hexagonal ammonium tungsten bronze (ATB) and tungsten oxide was discussed. Formation of ATB was controlled by parameters such as heating rate, sample mass and kind of atomosphere. Particle size of tungsten oxide was affected with amount of ATB formed in the intermediate, that is, particle size was very fine when ATB was formed in large quantities. Ultarfine individual particle of tungsten oxide was formed by a decomposing reaction from $\mathrm{ATB}$ to $\mathrm{WO}_{3}$ or $\mathrm{WO}_{2.9}$, and grain growth of its particle took place at temperatures above $873 \mathrm{~K}$.

\section{I 緒 言}

超硬合金の原料として使用されるタングステン粉末 はパラタングステン酸アンモニウム（A P T ）を熱分 解し, 得られた酸化タングステンを水素塞团気で還元 して製造されている。近年，精密加工技術の進歩に より超微粒の超硬合金の要求が増大している．酸化 タングステンの水素還元過程においてタングステン粉 末の粒度を支配する因子の研究は多数報告されている が1)，酸化タングステン生成過程における粒度を支配
する因子に関する研究は見当たらない。

酸化タングステン粒子の生成機構を明らかにするこ とは超微粒のW，WC粉末を製造する上できわめて重 要であると考える。

著者らは前報2ににおて結晶系の異なる A P Tの窒 素中での熱分解を調べ熱分解過程と酸化タングステン 微粒子の生成過程の関連を明らかにした。本報では 超微粒酸化タングステン粒子の生成に及ぼす熱分解雾 困気，加熱速度および充㙞量の影響を調べた。 


\section{II 実方法}

超硬合金の原料として用いられている単斜晶 $\mathrm{AP} T$ $\left(5\left(\mathrm{NH}_{4}\right)_{2} \mathrm{O} \cdot 12 \mathrm{WO}_{3} \cdot 5 \mathrm{H}_{2} \mathrm{O}\right.$, 以下A P Tと略記）の熱 分解を行った。使用したA P Tの密度および不純 物をTable 1 に示す。

熱分解実験は示差熱天秤を使用し， $1-6 \times 10^{-3} \mathrm{~kg}$ (3-16mmの粉末層厚) の A P Tをアルミナ製の試料容 器に充嫶し，0.017-0.25K/s の昇温速度，573-92 $3 \mathrm{~K}$ の温度範囲, 窒素, 酸素, アンモニアと窒素（い ゔれも純度 $99.999 \%$ ，露点203 K以下）の混合(1:1) ガスおよび空気中で熱分解した.

得られた熱分解生成物について，カンタソーブ比表 面積湘定器による比表面積湘定，X線回折(C u K $\alpha$ ) による生成物の同定，走查型電子顕微鏡による粒子形 態の観察を行い，熟分解反応における酸化タングステ ン超微粒子の生成過程を調べた。 また，超微粒子生 成につづく粒成長についても調ベた。

\section{III 実壆轺果および考察}

III－1 A P Tの加熱速度と熱分解生成物

安3 は A P T を空気中および真空中で分解した研究 において，生成する酸化タングステンの粒子形態が分 解する雾囲気で異なることを報告している。しかし， 酸化タングステン粒子の生成過 程と，その粓度を支配する因子 は明らかにされていない。

Fig. 1 にA P Tを $0.017 \mathrm{~K} / \mathrm{s}$ および0.17K/s の加熱速度， $573 \mathrm{~K}$ から $773 \mathrm{~K}$ までの種々の温 度まで空気中で加熱して得た分 解生成物のX線回折図形を示す。

$0.017 \mathrm{~K} / \mathrm{s}$ の加熱速度の場合， 生成物は $573 \mathrm{~K}$ まで無定形"1て あり，623K では六方晶アンモ ニウムタングステンブロンス (以下A T B と略記)*2 生成し


$\mathrm{B}$ と単斜晶 $\mathrm{WO}_{3}$ (以下 $\mathrm{WO}_{3}$ と 略記)の混合物となり，773K以



$0.17 \mathrm{~K} / \mathrm{s}$ の加熱速度の場合, 生成物は573KでA P Tであり， 623KではA P T が消失して A

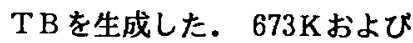

Table 1 Density and impurity contents of APT

\begin{tabular}{l|c}
\hline & Monoclinic APT \\
\hline Apparent density & $2.04 \quad \mathrm{Mg} / \mathrm{m}^{3}$ \\
F.S.S.S. & $45 \quad \mu \mathrm{m}$ \\
$\mathrm{As}, \mathrm{Ca}, \mathrm{Cr}, \mathrm{Cu}, \mathrm{Fe}, \mathrm{Mg}, \mathrm{Mn}, \mathrm{Ni}, \mathrm{Mo}$ & $<1 \mathrm{ppm}$ \\
$\mathrm{A} 1, \mathrm{Sn}$ & $<2 \quad \mathrm{ppm}$ \\
$\mathrm{Si}$ & $<5 \quad \mathrm{ppm}$ \\
\hline
\end{tabular}

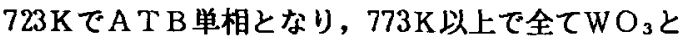
なった. 加熱速度による熱分解生成物の著しい 相違は，加熱速度が遅い場合，673K近傍からA T B と $\mathrm{WO}_{3}$ の共存温度域を経てWO 3 単相になるのに对し $\tau$, 加熱速度が速い場合, A T B 単相温度域を経て $773 \mathrm{~K}$ 近傍で $\mathrm{WO}_{3}$ 単相になることである。 また，加 熱速度が速い場合に573KでA P T が残存するのは， 加熱速度が速いために熱分解が遅れるためであると考 えられる.この熱分解の遅れはFig.5 に示す重量減 少曲線にも観察され，アンモニアと結晶水の解離に伴 う吸熱反応 '`および加熱速度が速い場合, 試料が均一 に加熱されないためと考えられる，窒素中における 熱分解では，773Kでも $\mathrm{A} \mathrm{T} \mathrm{B} \mathrm{とWO}{ }_{3}$ が共存した ${ }^{2}$.

これは空気中に比べ臺素中では A T B 中のアンモ二 アが分解されにくいためであると考えられる。

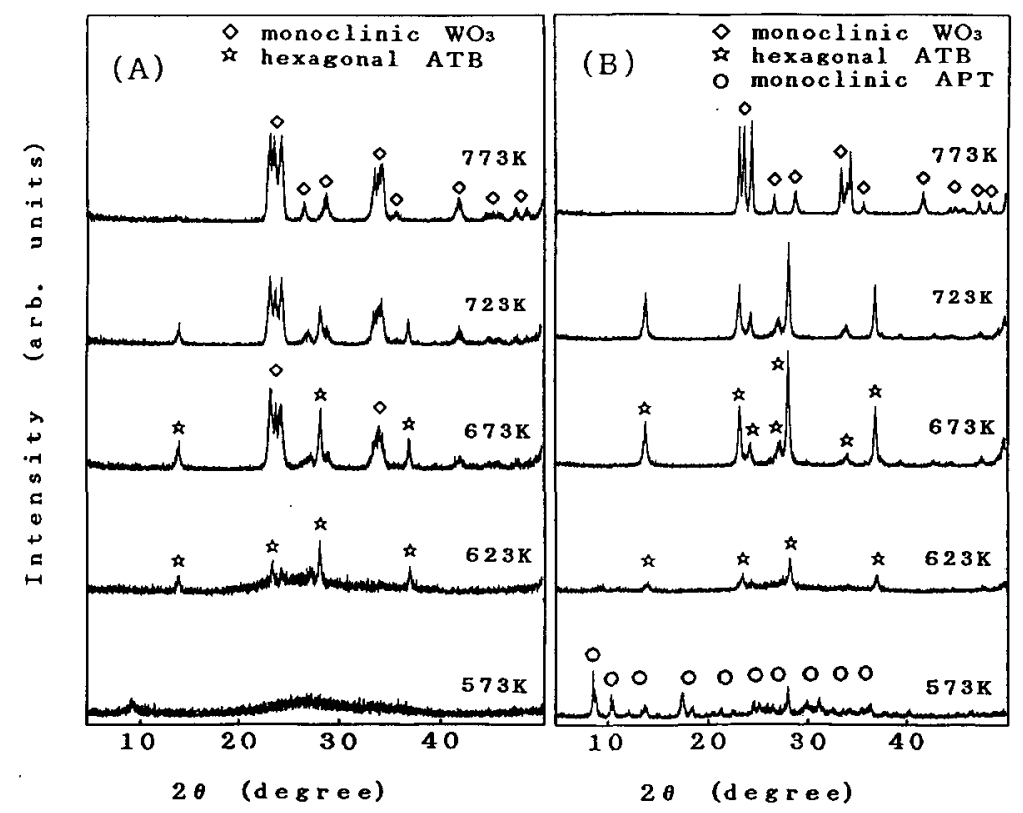

Fig. $1 X$-ray diffraction patterns of the decomposition intermediate of APT heated to various temperatures. (heated in air, sample mass : $4 \times 10^{-3} \mathrm{Kg}$ )

(A) heating rate : $0.017 \mathrm{~K} / \mathrm{s}$ (B) heating rate : $0.17 \mathrm{~K} / \mathrm{s}$ 


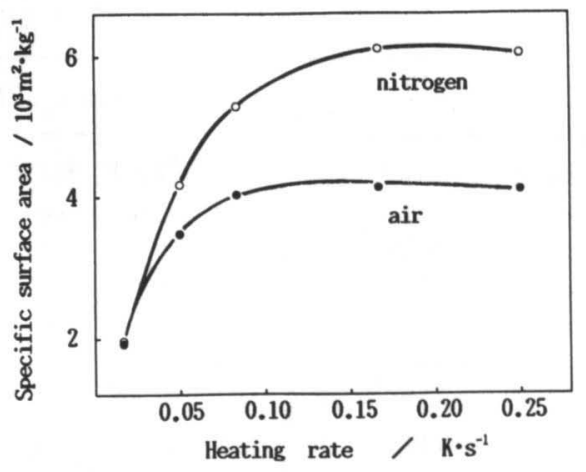

Fig.2 Effects of heating rate on specific surface area of $\mathrm{WO}_{3}$. (heated to $923 \mathrm{~K}$ in air and $\mathrm{N}_{2}$, sample mass : $4 \times 10^{-3} \mathrm{Kg}$ )

\section{III - 2 酸化タングステンの粒度に及ぼす加熱速度 の影響}

A P Tを0.017ー0.25K / $\mathrm{s}$ の加熱速度の空気中お よび窒素中で $923 \mathrm{~K}$ まで加熱して得た $\mathrm{WO}_{3}$ の比表面積 の変化をFig. 2 に示す. $0.017 \mathrm{~K} / \mathrm{s}$ の加熱速度に おいて雾囲気の違いによる比表面積の差は生じていな い. 加熱速度が速くなるに従って, 窒素中および空 気中ともに比表面積が大きくなり $\mathrm{WO}_{3}$ が微細化する ことを示している． 空気中に比べ窒素中での熱分解 の方がW $\mathrm{O}_{3}$ の微細化が著しい現象はW $\mathrm{O}_{3}$ の雾囲気に よる粒成長の差が起因していると考えられ，III－4 項 で検討を加えた。

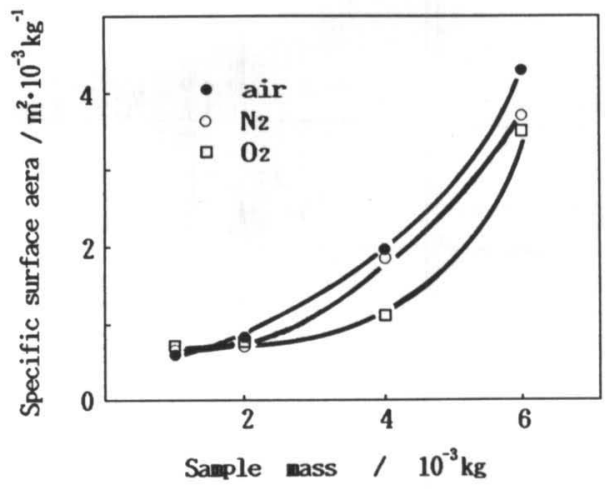

Fig. 3 Effects of sample mass and atmospheric gas on specific surface area of $\mathrm{WO}_{3}$.

(heated to $923 \mathrm{~K}$, heating rate : $0.017 \mathrm{~K} / \mathrm{s}$ )

*1 無定形A P T あるいは無定形アンモニウムタング ステンブロンズで, A P T の結晶水とアンモニア の約半分が分解した無定形の中間生成物である.

*2 $\quad\left(\mathrm{NH}_{4}\right) \times \mathrm{xO}_{3}$ で示され, $\mathrm{x}$ は0.25-0.33 の範囲と報 告4,5)されている.
III -3 酸化タングステンの粒度に及ぼす A P T 充填量および雾囲気の影響

Fig. 3 にA P Tの充填量と熱分解雲囲気を変えて 92 $3 \mathrm{~K}$ まで加熱した時に生成する $\mathrm{WO}_{3}$ の比表面積の変化 を示す. いずれの雲囲気中においてもその変化は類似 の挙動を示し, A P Tの充填量の増加とともにWO が微細化している。

Fig.4 に空気中で673Kまで加熱した時の生成物の 比表面積および生成物中の A T B と $\mathrm{WO}_{3}$ の X 線回折 強度のA P T 充填量に対する変化を示す. 充媜量の 増加による六方晶 A T B 量と比表面積の直線的な増加 はA P T粒子のスポンジ化の進行を示し，一次粒子を 微細化に導いていると考えられる.


まで加熱した時の重量減少曲線を示す． A P T 充填
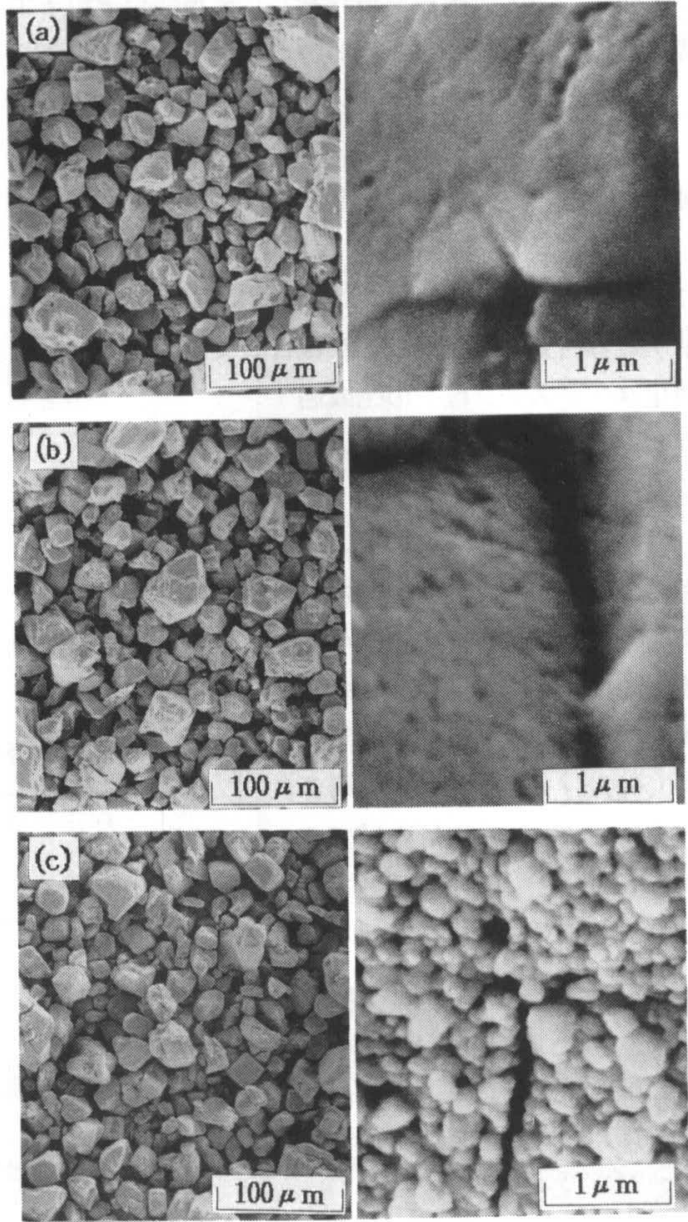

Photo.1 Scanning electron micrographs of $\mathrm{WO}_{3}$ decomposed on various sample mass.

(heated to $923 \mathrm{~K}$ in air, heating rate : $0.017 \mathrm{k} / \mathrm{s}$ )
(a) $1 \times 10^{-3} \mathrm{Kg}$
(b) $2 \times 10^{-3} \mathrm{Kg}$
(c) $6 \times 10^{-3} \mathrm{Kg}$

「粉体拉よび粉末治金」第 40 巻第 8 号 


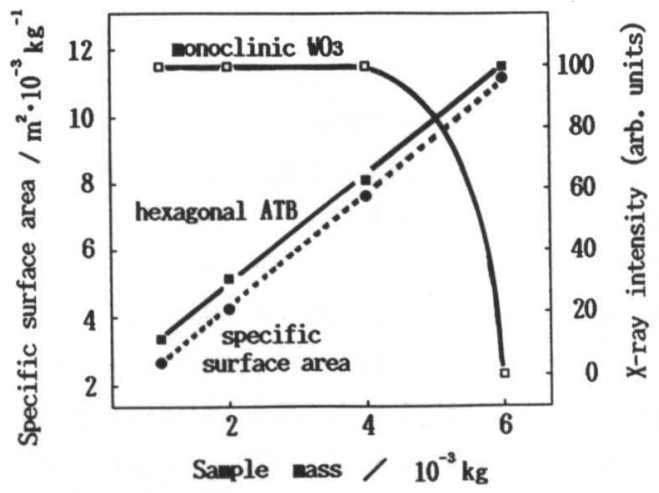

Fig.4 Effects of sample mass on specific surface area and crystalline phases of intermediate. (heated to $673 \mathrm{~K}$ in air, heating rate $: 0.017 \mathrm{~K} / \mathrm{s}$ )

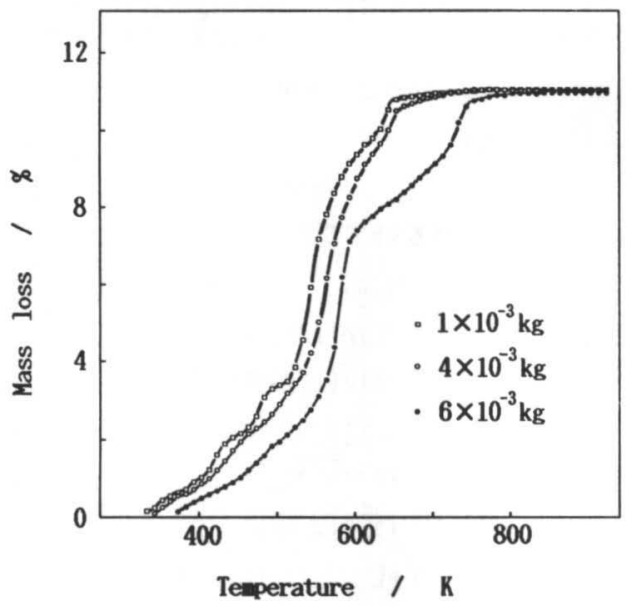

Fig.5 Change in mass loss curves with sample mass. (heated in air, heating rate : $0.017 \mathrm{~K} / \mathrm{s}$ )



Fig.6 Change in specific surface area and crystalline phase of decomposition intermediate of APT heated to various temperatures in mixture of $\mathrm{NH}_{3}$ and $\mathrm{N}_{2}$.
量の増加とともに熱分解が遅れ，重量減少曲線は高温 側にシフトしている. $6 \times 10^{-3} \mathrm{~kg}$ の充填量において $600 \mathrm{~K}$ 付近での重量減少の停滞はA P T中のアンモ二 アが安定な A T B に変化するからであることがFig.4 からも明らかである。

Photo.1 にAPTを923Kまで加熱して分解したW $\mathrm{O}_{3}$ の電子顕微鏡写真を示す. A P T 充填量の少な い場合の（a）は前報 ')で報告した窒素中で熱分解し たと同様のスポンジ化した粗い粒子であるのに対し， 充填量の多い ( c ) は微細なWO $\mathrm{W}_{3}$ の凝集体となってい る.（b )は ( a )と ( c )の中間の粒子形態である.

A T B は速い加熱速度および多い A P T 充填量の場 合に多く生成し，このような熱分解過程を経ると微細 なWO ${ }_{3}$ が得られることが明らかになった。

Fig.6 にアンモニアと窒素の混合ガス中で種々の温 度で熱分解した生成物の比表面積変化と X線回折によ る結晶相の同定結果を示す。 Photo. 2 に $823 \mathrm{~K}$ と 923 Kにおける生成物の電子顕微鏡写真を示す. $773 \mathrm{~K}$ 迄は窒素および空気中とほぼ同様の熱分解挙動を示し たが, $823 \mathrm{~K}$ 以上で異なった挙動をした。すなわち, $823 \mathrm{~K}$ の高温までA T B は安定に存在し, 粒子形態は スポンジ化したAT B 粒子上に微細な一次粒子が形成 （a ）し始めた. $823 \mathrm{~K}$ から還元反応が進行し, $\mathrm{WO}_{3}$


Photo.2 Scanning electron micrographs of tungsten oxide obtained in decomposition in $\mathrm{NH}_{3}$ and $\mathrm{N}_{2}$ mixture. (sample mass : $4 \times 10^{-3} \mathrm{Kg}$, heating rate : $0.017 \mathrm{~K} / \mathrm{s}$ )
(a) heated to $823 \mathrm{~K}$
(b) heated to $923 \mathrm{~K}$ 
を生成することなしに A T B から正方晶 $\mathrm{WO}_{2.90}$ へ変 化した. この変化に対応して比表面積が増加し, 非 常に微細な $\mathrm{WO}_{2.90}$ の一次粒子が形成 (b)されている ことを示している.

これらの粒子形態および粒度の変化はいずれの熱分 解雲囲気においても結晶系の変化に伴って生じている と考えられる. すなわち, 無定形から六方晶A T B るいは単斜晶 $\mathrm{WO}_{3}$ に変化する場合は粒子形態の変化 がないのに対し, 六方晶 $\mathrm{AT}$ T B から単斜晶 $\mathrm{WO}_{3}$ ある るいは正方晶 $\mathrm{WO}_{2}$. 90に変化する際は一次粒子が形成 される.

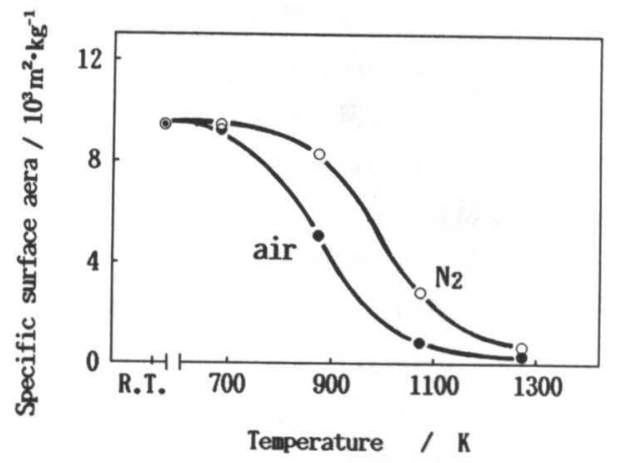

Fig. 7 Influence of heat treatment on specific surface area of $\mathrm{WO}_{3}$.
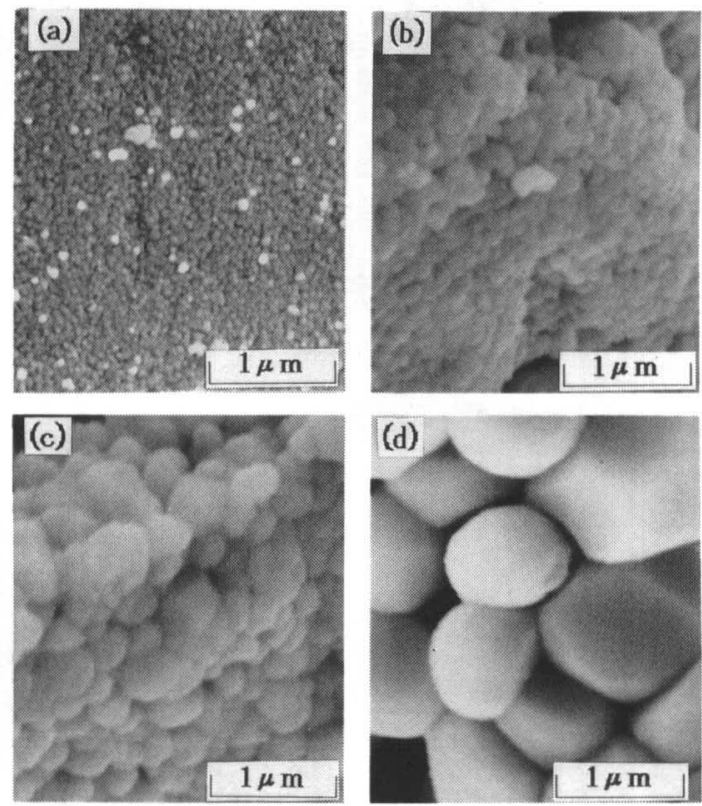

Photo.3 Scanning electron micrographs of $\mathrm{WO}_{3}$ heated to various temperature in air.
(a) raw tungsten oxide,
(b) $873 \mathrm{~K}$
(c) $1073 \mathrm{~K}$
(d) $1273 \mathrm{~K}$

III -4 酸化タングステンの粒成長

加熱過程における一次粒子の粒成長を明らかにする ために, 微細なWO $\mathrm{WO}_{3}$ を空気および咥素中で $673 \mathrm{~K}$ から $1273 \mathrm{~K}$ までの種々の温度まで加熱し比表面積と形態の 変化を調べた. Fig.7 に比表面積の変化, Photo.3

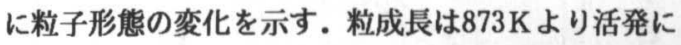
起こり, 窒素中よりも空気中での成長が大きかった.

Fig.2 において窒素および空気中ともに速い加熱速 度では中間生成物として六方晶 A T B 単相を生成する 熱分解条件にもかかわらず, 空気中で生成したWO 3 が粗くなるのは一次粒子が生成した後の粒成長の差に 起因していると考えられる.

\section{IV 結 論}

A P T の熱分解による酸化タングステン微粒子の生 成に及ぼす熱分解雾囲気, 加熱速度およびA P T 充填 量の影響を調べ以下のことが明らかになった。

（1）A P Tの熱分解において加熱速度が速い場合およ びA P T充填量が多い場合, 加熱温度の上昇に伴

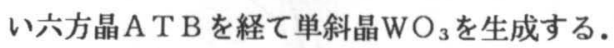

(2)加熱速度が遅い場合およびA P T 充堑量が少ない

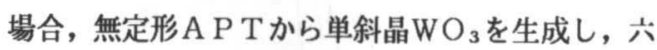



(3)アンモニアと窒素の混合ガス中での A P T 熱分解 は六方晶 $\mathrm{A} T \mathrm{~T}$ を経て正方晶 $\mathrm{WO}_{2.90}$ を生成する。 (4)生成する単斜晶 $\mathrm{WO}_{3}$ および正方晶 $\mathrm{WO}_{2.90}$ の粒度 は熱分解過程で生成する六方晶 A T B の生成量に 依存する. 加熱速度が速いほど, A P T 充填量が 多いほど六方晶 A T B の生成量が多くなり微細な 一次粒子となる.

(5)単斜晶 $\mathrm{WO}_{3}$ の粒成長は $873 \mathrm{~K} よ り$ 活発になり, 一 次粒子の粗大化が生じる.

\section{文献}

1)たとえば, R.Haubner,W.D.Schubert,H.Hellmer,E. Lassner,B.Lux:J.Refractory Metals and Hard Materials,3 (1983) 156.

2)山本良治, 郷谷清, 志垣憲良: 粉体および粉末治金, 投稿中.

3)安永强:粉体および粉末治金,8（1961）253.

4)P.G.Dickens, A.C.Halliwell,D.J.Murphy and M.S. Wittingham:Trans.Farad.Soc.,67 (1971) 794.

5)J.W.van Put,T.W.Zegers and H.Liu:J.Refractory Metals and Hard Materials,10 (1991) 123.

6)山本良治, 山田正二,本川惺, 志垣憲良:粉体および 粉末冶金，投稿中. 